\title{
Koku İhtiva Eden Ağaç Odunlarının Peyzaj Mimarlığı Uygulamalarında Kullanımına İlişkin Genel Bir Değerlendirme
}

\author{
Göksu ŞiRiN ${ }^{1}$, Mehmet TOPAY2* \\ ORCID 1: 0000-0003-1393-1697 \\ ORCID 2: 0000-0002-3897-1756 \\ ${ }^{1}$ Gaziosmanpaşa Üniversitesi, Almus Meslek Yüksekokulu, Ormancılık ve Orman Ürünleri Programı, 60150, Tokat, Türkiye. \\ ${ }^{2}$ Süleyman Demirel Üniversitesi, Mimarlık Fakültesi, Peyzaj Mimarlığı Bölümü, 32260, Isparta, Türkiye. \\ *e-mail: mehmettopay@sdu.edu.tr

\section{Öz} \\ Ahşap, teknolojik ve estetik özellikleriyle birçok farklı türü olan teknik bir malzemedir. Bu özellikleriyle insanoğlu \\ ahşabı günümüze kadar çeşitli amaçlarla kullanmıştır. Peyzaj mimarlığı uygulamalarında da ahşap, gerek \\ teknolojik özellikleri gerekse estetik yapısıyla vazgeçilmez bir malzemedir. Ahşabın estetik özelliklerinden biri \\ olan güzel koku özelliği de mimari tasarımlarda tasarımı yönlendirebilecek unsurlardan biri olabilir. Özellikle \\ ardıç, servi, sedir ve çam gibi bazı ağaç türleri içerdikleri etkin, güzel ve farklı kokularla tasarımlara olumlu \\ katkılar sağlayabilirler ve bu nedenle dış mekân donatılarının imalatında diğerlerine göre daha çok tercih \\ edilebilirler.
}

Anahter Kelimeler: Peyzaj, ahşap, ağaç malzeme, koku

\section{An Overview of the Use of Odorous Wood in Landscape Architecture Applications}

\begin{abstract}
Wood is technical equipment with its technological and aesthetic features. Wood material has been used by people for various purposes until today. In landscape architecture applications, wood is an indispensable material with its technological features and aesthetic structure. One of the aesthetic properties of wood, the fragrance feature can be one of the elements that can guide design in architectural designs. Some tree species, especially juniper, cypress, cedar, and pine can contribute positively effect to the designs therefore; they are more preferable in the manufacture of outdoor equipment than others.
\end{abstract}

Keywords: Landscape, wood, wood material, odor

\section{Giriş}

Ağaç malzeme insanoğlunun ihtiyaçlarını karşılamak için kullandığı en eski malzemelerdendir (Gündüz ve ark., 2009). Ağaç malzemenin en önemli özelliği birbirinden farklı binlerce türü olmasıdır. Dünyada 20.000 'in üzerinde ağaç türü vardır. Ağaç türleri; renkleri, dokuları, sertlikleri, taşıma kabiliyetleri, boya tutma kabiliyetleri, kurutulma kolaylıkları, lif düzgünlükleriyle birbirinden ayrılmaktadırlar (Beceren Öztürk, 2005). Ahşap doğru kullanılırsa oldukça dayanıklı (Canbakal Ataoğlu, 2016) bir malzeme olmakla beraber yenilenebilir ve biyolojik olarak da dönüştürülebilir bir malzemedir.

Atıf: Şirin, G., Topay, M. (2019). Koku İhtiyva Eden Ağaç Odunlarının Peyzaj Mimarlığı Uygulamalarında Kullanımına İlişkin Genel Bir Değerlendirme. Mimarlık Bilimleri ve Uygulamaları Dergisi (MBUD), 4 (1), 90-96.

DOI: $\underline{10.30785 / \mathrm{mbud} .543191}$ 
Ağırlığına oranla son derece yüksek dayanıklıık ve sertliğe sahip oluşu, özellikle inşaat ve mühendislik amaçıı kullanımlarda ahşabı son derece etkili ve değerli bir malzeme yapmaktadır (Şirin ve Aydemir, 2016).

Ahşabın en önemli kullanım sebeplerinden biri malzemenin insanlarda oluşturduğu olumlu etkidir ve diğer özelliklerinin yanında estetik özelliği de önem taşımaktadır. Estetik açıdan bakıldığında ahşap dekoratif bir malzemedir. Her ağacın kendisine özgü renk, desen ve kokusunun oluşu, hatta desenin, ağacın biçme ve kesim yönüne göre değişmesi değerli estetik özelliklerdir. Tür çeşitliği dikkate alındığında ahşap malzemenin, her zevke hitap edecek renk ve desende bulunması mümkündür. Ahşap, doğal bir yapı malzemesi olduğundan, ahşap yapılar insan sağlığı için de tehlike oluşturmamaktadırlar. Özellikle gerekli yalıtımların yapıldığı modern ahşap konutlar, iç mekân hava kalitesi ve mekân konforu bakımından insan yaşamı ve sağlığı için önemli yapılardır (Topay ve Kuş Şahin, 2016; Frühwald ve Pohlmann 2002). Kolayca yenilenebilen ve esnek tasarımlara cevap verebilen bir malzeme olmasıyla (Beceren Öztürk, 2005) peyzaj mimarlığı uygulamalarında ahşap önemli materyallerden biridir. Estetik olarak diğer malzemelerle ve doğa ile uyumludur. Doğallığın ve estetik görünüşün ön planda olduğu dış mekân düzenlemeleri ve donatı elemanlarının imalinde peyzaj mimarları, endüstri ürünleri tasarımcıları gibi disiplinler ahşap esaslı malzemelerden yoğun şekilde faydalanmayı tercih etmektedirler (De Cristoforo, 1976; Winterbottom, 2000; Topay ve Kuş Şahin, 2016). İ̧̧ ve dış mekânlardaki peyzaj mimarlığı uygulamalarında farklı amaçlarla kullanılan ahşap, birçok türü olması sayesinde kullanım yeri, kullanım beklentileri ve istekleri için tasarımcılara seçenekler oluşturmaktadır. Ahşap kullanımına başlıca neden olarak malzemenin görsellik anlamında kullanıcılara sağladığı (De Cristoforo, 1976; Winterbottom, 2000; Topay ve Kuş Şahin, 2016) etkiyle beraber düşük yoğunlukta bile yüksek dirence sahip olması, hafif olması sebebiyle özellikle çatı sistemlerine sahip pergola, çardak, gazebo gibi yapılarda ya da dayanım isteyen veya aşınma sorunu yaşanabilecek olan döşeme vb. yük taşıyıcı donatı elemanlarında rahatlıkla kullanılabilmesi, ses, Isı ve elektrik iletkenliğinin az olması, kimyasal maddelere karşı dayanıklı olması, geri dönüşümlü doğal bir materyal olması, işlenme özelliklerinin iyi olması, tutkallanma, boyanma, verniklenme özelliğine sahip olması, tadilat işlemlerinin ucuz, kolay ve temiz olması, temininin kolay olması (Bozkurt ve ark., 1993) gibi son derece önemli diğer nedenler sayılabilir. Ahşap malzemelerin yoğun olarak tercih edildiği alanlara örnek olarak; kent ve mahalle parkları, konut bahçeleri, çocuk oyun alanları, spor alanları, meydanlar, hayvanat bahçeleri vb. verilebilir (Cristoforo, 1976; Karadağ ve Ark. 2009; Topay ve Kuş Şahin, 2016).

Doğru malzeme seçiminin dışında mimari tasarımlarda dikkat edilen hususlardan biri de insanların bulundukları mekânlarda kendilerini iyi hissetmeleri ve mekânı iyi hatırlayarak yeniden ziyaret etmeleri ya da gerekli bazı zamanlarda bu mekânları kullanmak için tercih etmelerini sağlayacak etkinin ve uygunluğunun oluşturulmasıdır. İnsanlar mekânları duyuları ile algılarlar. Bir mekânda zaman geçirmek ya da o mekânı hatırlamada, mekânı tarif etmede mekânın karakteristiğini oluşturan ve insan duyularına hitap eden özellikler önemlidir. İnsan beş duyu aracılığıyla görür, duyar, tadar, koklar, dokunur ve tüm duyuların topladıklarını birbiriyle ilişkilendirerek hisseder ve kavrar. Bu bağlamda; fiziksel mekân imgelerle görülür renk, doku, koku, tat, ses ile tanımlanır ve anlam kazanır (Gezer, 2012). Ahşap malzeme insanların estetik, güven gibi duygularına rengi, dokusu, deseni, kokusu, sağlamlığı ile olumlu yönde hitap etmesiyle bir mekânı tanımlama, hatırlama, değerlendirme, tercih etme konusunda hem peyzaj mimarları hem de kullanıcılar için etkili bir malzemedir. Peyzaj mimarlığı uygulamalarında; peyzaj çoğunlukla doğal elemanlardan oluşan ve zaman içinde gelişen bir çevreyi anlatırken, mimarlık inşai nitelikte, daha başından tamamlanmış ve zaman içinde yaşlanacak bir yapıtı çağrıştırmaktadır (Aslanoğlu Evyapan ve Tokol, 2000). Şekil 1'de farklı ahşap donatı elemanı örnekleri görülmektedir. 

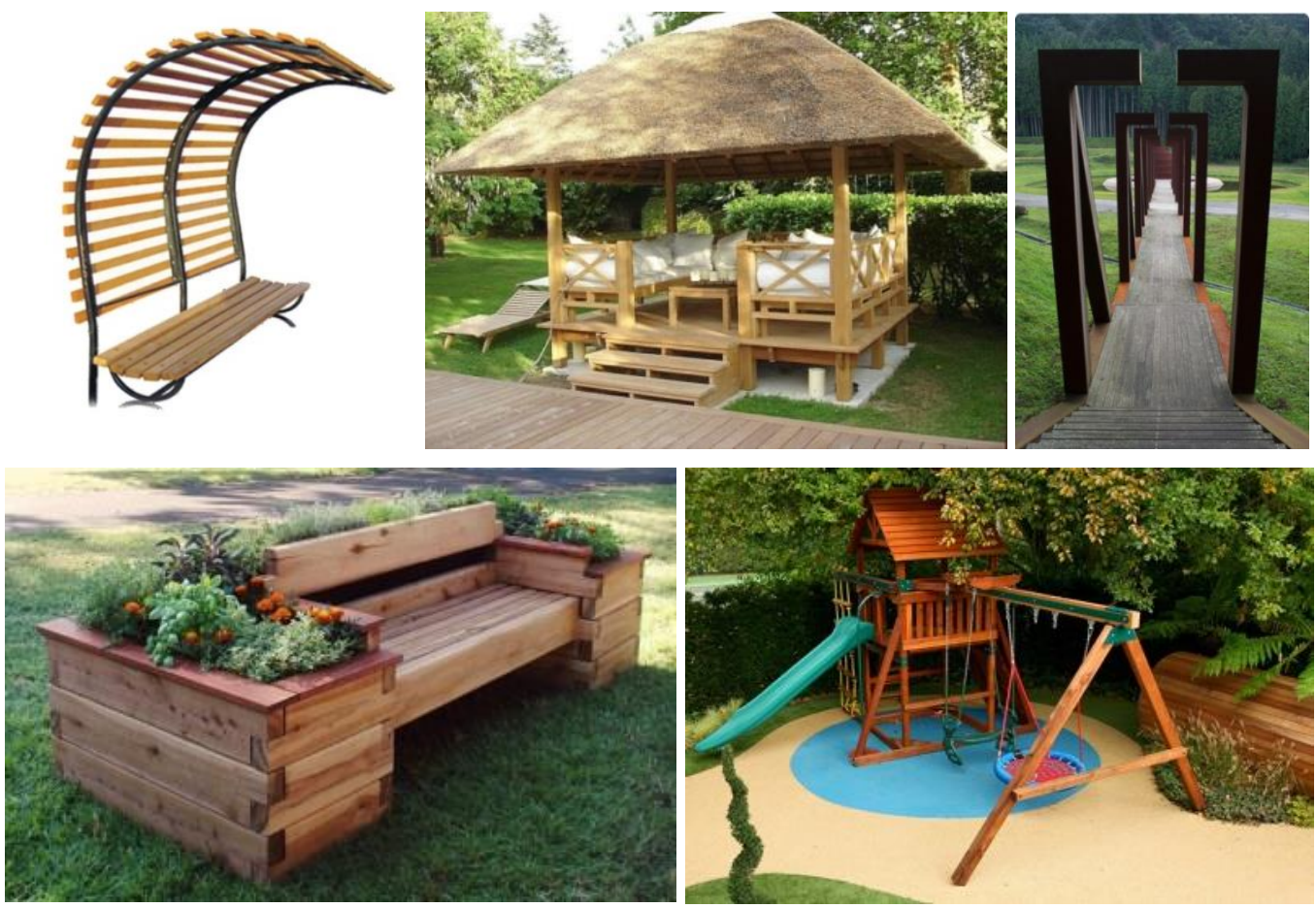

Şekil 1. Ahşap malzeme ile üretilmiş farklı donatı elemanları

Bu anlamda kent içi ve kent dışı tüm peyzaj planlama süreçlerinde doğal, kolay şekillendirilebilir, birçok farklı amaç için kullanılabilir ve eskidiğinde yenilenebilir bir malzeme olan ahşabın peyzaj mimarı eli ile istenildiği şekilde ve istenilen özelliği ile kullanılması hem önemli hem de oldukça değerlidir.

Tüm fiziksel özelliklerinin içerisinde ahşabı diğer doğal malzemelerden ve yapay malzemelerden ayıran farklı estetik özelliklerden biri kendine has ve bazı ağaçlarda oldukça etkili olan "koku" özelliğidir.

\subsection{Koku}

Koku, koku alma duyusu ile algılanabilen, genelde çok küçük konsantrasyonda havada çözünmüş olarak bulunan kimyasal maddelerden her biridir (Kandemir ve Bayar Muluk, 2016). İnsanoğlu kokuyu çok eski dönemlerden beri çeşitli sebeplerle kullanmaktadır. Güzel kokular insanları etkileyerek bulundukları yer ve durumu olumlu algılamalarını sağlar. Koku beyindeki koku merkezine ulaştığında beyin daha önceki deneyimlerle kazanılmış olan şifrelere dayanarak o kokuyu tanır. Beyin, duygular ve hafızayla birlikte bütün bir sistem olarak çalışır. Bu nedenle, genellikle alınan bir kokuyla, bu kokuya ilişkin biriken deneyimler anımsanır. Koku, mekânlarda, mekânı özel kılan bir uyarıcıdır (Gezer, 2012).

\subsection{Koku ihtiva eden ağaç malzemenin kullanım olanakları}

Ağaçlar içerdikleri bazı kimyasal maddeler ile kendilerine has kokulara sahiplerdir. Yapraklı ve iğne yapraklı ağaç odunlarının ihtiva ettikleri eterik yağlar ait oldukları ağaç türleri odunlarının teşhisinde de birer yardımcı faktör olmaktadırlar. Odunun mekanik ve kimyasal şekil ve suretlerle işlenmesi sırasında açığa verdikleri özel kokular, ihtiva ettikleri eterik yağlar sebebiyle olup ekseriya hoşa gidecek özelliktedirler (Huş, 1958). Bazı ağaçlarda koku yok denecek kadar azken bazılarında sadece taze halde koku hissedilmektedir ve bu koku zaman içinde kaybolmaktadır. Eski dönemlere ait ahşap yapılarda yapılan çalışmalarda kullanılacak ahşabın seçiminde örneğin mobilya yapımında, mezar yapımlarında, panolarda, bina iç ve dış kısımlarında yontmaya elverişlilik, nem ve basınca dayanıkııık gibi teknolojik özelliklerin göz önünde bulundurulmasının yanında estetik yönden olumlu etki doğuran renk ve koku özelliklerinin de düşünüldüğü görülmektedir (Aytuğ ve Görcelioğlu, 1987). Kimi mobilyalarda güzel kokulu ağaçların tercih edilmesi mekânda özellikli bir koku istenmesindendir. Bazı ağaçların tercih edilmesindeki bir diğer önemli neden kokuyu sağlayan kimyasalların aynı zamanda çeşitli parazitlerin tasallutuna da engel olmasıdır. Ağaçların içerdiği koku, renk, tat gibi özellikleri 
sağlayan ekstraktif maddelerin fazlalığının bazı ağaçlarda doğal dayanımı artırdığı bilinmektedir. Ağaç türlerinin dayanımı, böcek ve mantar zararları gibi biyotik etkilerle rüzgâr, kar, yağmur, güneş ışığı, çeşitli aşındırıcı etkiler gibi abiyotik etkilere karşı gösterilen dirençtir. Ağacın doğal rengi ve görünümünün bozulmaması gereken dekoratif çalışmalarda doğal dayanım özelliği önemlidir (Sivrikaya, 2008).

Ağaçlarda koku kabuk, yaprak, çiçek, meyve, tohum ve odun kısımlarında oluşabilmektedir.

Peyzaj mimarlığı uygulamalarında güzel koku sağlaması nedeniyle ağaçlar canlı halde kullanıldığı gibi bazı tasarımlarda mekânların açık ve kapalı alanlarında çeşitli donatı elemanlarında sıklıkla kullanılmaktadır. Peyzaj donatı elemanları, cadde, sokak, yol, meydanlar ve rekreasyon alanlarında insanın ve toplumun, çok yönlü gereksinimlerini karşılayan, mekana kimlik kazandıran, yaşamı kolaylaştıran, çevre kalitesini artıran, hareketli ve değişken özellikte yardımcı peyzaj elemanlarıdır (Başal ve ark., 1997; Karadağ ve ark., 2016). Donatı elemanları; zemin kaplamaları (beton, taş, ahşap vb.), oturma birimleri (banklar, sandalyeler vb.), aydınlatma elemanları, işaret ve bilgi levhaları, sınırlandırıcılar (yaya bariyerleri, caydırıcılar vb.), su öğesi (çeşmeler, kanallar, süs havuzları vb.), üst örtü öğeleri (pergola, gazebo vb.), satış birimleri (büfeler, sergi pavyonları vb.), sanatsal objeler (heykeller vb.), diğer öğeler (çöp kutuları, posta kutuları, çiçeklikler, bilet otomatları, bisiklet park yerleri, saatler, bayrak direkleri vb.) olarak sayılabilir (Süel Yazıcı, 2007; Karadağ ve ark., 2016). Tüm bu yapılarda kullanılabilen ahşap malzeme hem düşünülen fonksiyon hem de estetik özelliğine göre seçilmektedir.

Koku özelliği ile de kullanıcıların duyu organlarına hitap edebilen donatı elemanları, peyzaj mimarlığı uygulamalarında yer alan çevre donatı elemanlarının konforlu bir şekilde kullanımı konusunda pozitif katkılar sağlayabilir. Doğal bir kokuya sahip oturma biriminde oturuyor olmak kullanıcının kendisini doğanın içinde hissetmesi ya da onun bir parçasıymış gibi hissetmesini sağlayabilir. Özellikle insanlar açısından kısıtlı ve/veya zor yaşam koşulları sağlayan kentsel ortamlarda kullanılacak donatı elemanlarının bu tür bir özelliğe sahip olması tasarımlara ve kullanıcılara olumsu yansımalar sağlayacaktır. Bu bağlamda Türkiye'de yetişen ve koku özelliğine sahip olan bazı ağaçlar ile bu ağaçlara ait koku özelliği ve yetişme ortamı bilgileri ve kullanım alanları Tablo 1'de verilmiştir.

Tablo 1'de Türkiye'de yetişen bazı ağaç türlerine ait koku özellikleri, kullanım alanları ve yetişme bölgeleri gösterilmiştir.

Tablo 1. Türkiye'de yetişen odunu güzel koku ihtiva eden bazı ağaçların yetişme alanları ve kullanım yerleri (Doğu ve ark., 2001; As ve ark., 2001; Akkemik, 2018)

\begin{tabular}{llll}
\hline Ağaç Adı & Koku Özelliği & Yetişme Alanları & Kullanım Alanları \\
\hline $\begin{array}{l}\text { Kokulu Ardıç } \\
\text { (Juniperus } \\
\text { foetidissima Milld.) }\end{array}$ & $\begin{array}{l}\text { Odunu kendine has } \\
\text { hoş kokulu }\end{array}$ & $\begin{array}{l}\text { Kuzey Türkiye, Batı, } \\
\text { Güney ve Orta Anadolu } \\
\text { Balkanlar Transkafkasya } \\
\text { Suriye Kıbrıs }\end{array}$ & $\begin{array}{l}\text { Tel direği (telefon, elektrik ve } \\
\text { diğerleri), maden direği, sandık, } \\
\text { dam örtüsü, mobilya, çit yapımı, } \\
\text { tornacılık }\end{array}$ \\
\hline $\begin{array}{l}\text { Sarıçam (Pinus } \\
\text { sylvestris L.) }\end{array}$ & Reçine kokulu & Kuzey, Orta ve Doğu & $\begin{array}{l}\text { Çit, tel direği (telefon, elektrik } \\
\text { ve diğerleri), maden direği, yapı } \\
\text { iskelesi, travers, bina inşaatı, } \\
\text { köprü, deniz araçları, mobilya }\end{array}$ \\
\hline $\begin{array}{l}\text { Lübnan Sediri } \\
\text { (Cedrus libani A. } \\
\text { Rich.) }\end{array}$ & $\begin{array}{l}\text { Anadolu Sibirya Kafkasya } \\
\text { hoş kokulu Bu koku }\end{array}$ & Toros Dağları Lübnan & $\begin{array}{l}\text { Toprakla temas eden yerler, tel } \\
\text { direği (telefon, elektrik ve } \\
\text { diğerleri), çit yapımı, köprüler, } \\
\text { bina iç ve dış dekorasyonu, } \\
\text { mobilya, bahçe mobilyası }\end{array}$ \\
\hline $\begin{array}{l}\text { Akdeniz Servisi } \\
\text { (Cupressus } \\
\text { sempervirens L.) }\end{array}$ & $\begin{array}{l}\text { Odunu kendine has } \\
\text { hoş kokulu }\end{array}$ & $\begin{array}{l}\text { Güney Anadolu Doğu } \\
\text { Akdeniz İran }\end{array}$ & Çit, su altı inşaatı
\end{tabular}


Türkiye'de donatı elemanlarında en çok tercih edilen yerli ağaç türlerinden Sarıçam (Pinus sylvestris L.) ve Sedir (Cedrus libani A. Rich.) kokuları ile de dikkat çeken türlerdir. Yine peyzaj alanlarında odunu kullanılan Kokulu ardıç (Juniperus foetidissima Milld.), Akdeniz servisi (Cupressus sempervirens L.) türleri de ihtiva ettikleri güzel koku sayesinde diğer ağaçlardan ayrılmaktadır.

Ahşabı koku özelliğin sahip olan ancak ülkemizde yetişmeyip yurt dışından getirtilen bazı odun türleri de mevcuttur. Bu türlerinde peyzaj uygulamalarında yer alması konforu arttırmak bakımından katkı sağlayacaktır. Tablo 2'de Türkiye' de kullanılan yabancı bazı ağaç türlerine ait koku özellikleri, kullanım alanları ve yetişme bölgeleri gösterilmiştir.

Tablo 2. Türkiye'de kullanılan odunu güzel koku ihtiva eden bazı yabancı tür ağaçların yetişme alanları ve kullanım yerleri (Göker ve Kurtoğlu, 1987)

\begin{tabular}{|c|c|c|c|}
\hline Ağaç Adı & Koku Özelliği & Yetişme Alanları & Kullanım Alanları \\
\hline $\begin{array}{l}\text { Anigre } \\
\text { (Pouteria spp.) }\end{array}$ & $\begin{array}{l}\text { Odunu hafif sedir } \\
\text { kokusunu andırır }\end{array}$ & $\begin{array}{l}\text { Gine, Kamerun, Zaire, } \\
\text { Uganda, Angola }\end{array}$ & $\begin{array}{l}\text { Kaplamacılık, mobilya, } \\
\text { binalarda iç ve dış } \\
\text { dekorasyonda }\end{array}$ \\
\hline $\begin{array}{l}\text { Dibetou (Lovoa } \\
\text { trichilioides) }\end{array}$ & $\begin{array}{l}\text { Kendine has kokusu } \\
\text { oldukça fazla }\end{array}$ & $\begin{array}{l}\text { Sierra Leone, Liberya, Fildişi } \\
\text { sahiline, Gana, Nijerya, } \\
\text { Kamerun, Gabon, Kongo }\end{array}$ & $\begin{array}{l}\text { Mobilya endüstrisinde hem } \\
\text { masif hem de kaplamada }\end{array}$ \\
\hline $\begin{array}{l}\text { Tola Branca } \\
\text { (Gossweilerodendr } \\
\text { on balsamiferum) }\end{array}$ & $\begin{array}{l}\text { Kerestesi doğal sakız } \\
\text { içerdiği için hafif bir } \\
\text { kokuya sahiptir. }\end{array}$ & $\begin{array}{l}\text { Nijerya, Kamerun, Gabon, } \\
\text { Kongo, Angola, Zaire }\end{array}$ & $\begin{array}{l}\text { Dekoratif kaplamalar, } \\
\text { kontrplak, binalarda iç ve dış } \\
\text { dekorasyonda mobilya, } \\
\text { parke, fazla direnç } \\
\text { istemeyen yerler }\end{array}$ \\
\hline $\begin{array}{l}\text { Kotibe } \\
\text { (Nesogordonia } \\
\text { papaverifera) }\end{array}$ & Kendine has kokulu & $\begin{array}{l}\text { Fildişi Sahili, Gana, Nijerya, } \\
\text { Kamerun, Gabon, Kongo }\end{array}$ & $\begin{array}{l}\text { Döşeme, parke, kontrplak, } \\
\text { kaplama, mobilya }\end{array}$ \\
\hline
\end{tabular}

Tablo 1 ve Tablo 2'de görülen ağaçlar kullanım yerleri bakımından oldukça fazla farklııklar göstermektedir. Bu farklılıklar ağaç odunlarının anatomik, fiziksel, kimyasal ve mekanik özelliklerinden kaynaklanmaktadır (Bozkurt, 1986). Dolayısıyla peyzaj uygulamalarının farklı bölümlerinde bu odunların teknik özellikleri dikkate alınarak bir seçim yapmak olanaklı olabilir. Ancak, kokunun sürekliliği açısından bu tür odunların dış mekânda kullanılıyor olması bir dezavantaj oluşturabilir. Zamanla, uygulamalarda kullanılan bu ahşap malzeme koku özelliğini kaybedecektir. Bu nedenle bakım çalışmaları rutin olarak yapılmalı ve bu özellik mümkün olduğunca korunmalıdır.

\section{Sonuç ve Öneriler}

Ağaç malzeme eski dönemlerden günümüze kadar işlenme kolaylığı, bulunabilme, yenilenme, eskidiğinde kolayca imha edilebilme gibi sebeplerle kullanılmaya devam etmektedir. Teknolojik özelliklerinin yanında estetik açıdan da insanların hem iç hem de dış mekânlarda özellikle tercih ettiği bir malzemedir. Insanlar yaşadıkları ve bulundukları ortamların kendi ruh ve beden sağlıklarına iyi gelmesini istemektedirler. Bu nedenle iş ve dinlenme alanlarında ve zamanlarında, duyularına olumlu yönde hitap edecek ortamları oluşturmaya çalışırlar. Peyzaj mimarları sıkça kullandıkları doğal bir malzeme olan ahşapla bu duygulara hitap etmeye çalışmaktadır. Mimari tasarımlarda, bazı ağaç odunları intiva ettikleri güzel kokular sebebi ile kullanılmaktadır. Ancak bir ağaç türünün kullanımı için sadece koku özelliği yeterli olmamaktadır. Kimi ağaçlar odununda bulunan güzel kokuyla birlikte yeterli teknolojik özellikte olmadığından mimaride değerlendirilememektedir. Buna karşlık hem Türkiye'de bulunan hem de yabancı bazı tür ağaç odunları içerdikleri güzel kokuyla beraber dayanımları, teknolojik özelliklerinin yüksekliği ile birçok farklı amaçla kullanılabilmektedir. Bu kullanım imkânları tasarımcıların, tasarımda geniş bir yelpazede rahatılıla hareket etmelerine olanak vermektedir. 
Hemen hemen her ülke kendi coğrafyası ve yakın ya da uzak diğer bölgelerde koku özelliği için birçok farklı ağaç türüne ulaşabilmektedir. Türkiye iklimsel açıdan birçok farklı tür ağacın yetişebildiği bir coğrafyadır. Bu coğrafya içinde istenen özellikteki çeşitli ağaçlara ulaşma imkânı mevcuttur. Peyzaj tasarımlarında hem kalite hem özellik hem ulaşılabilirlik hem de ekonomik yönden bu durum avantaj sağlamaktadır.

Bu çalışmada ahşapta koku özelliği ve güzel kokulu odunların peyzaj mimarlığı uygulamaları açısından kullanımına genel olarak değinilmiştir. Ağaç malzemede oluşan koku ağacın içerdiği kimyasal maddelerle alakalıdır. Bu kimyasallar bazı ağaç odunları için parazitleri uzak tutma özelliği de sağlamaktadır. Ağaç malzeme kullanım yeri için teknolojik ve estetik özellikleri bir arada değerlendirilerek seçilebilir. Her ağacın özellikleri hem türler arasında hem de kendi içinde dahi farklılıklar gösterdiğinden kullanım yeri için önemli bir bilgi birikimi ve tecrübe gerekmektedir. Buna göre ahşabın kokusu, teknolojik özellikleri ve peyzaj mimarlığı uygulamalarında bu özellikleri ile kullanımına ilişkin daha fazla sayıda çalışma yapılması konuyla ilgili çalışanlar için faydalı olacaktır.

\section{Kaynaklar}

Akkemik, Ü. (2018). Türkiye'nin Doğal-Egzotik Ağaç ve Çalıları, T.C. Orman ve Su Iş̧leri Bakanlı̆̆ı Orman Genel Müdürlüğü Yayınları, ISBN: 978-605-9550-14-7, Ankara, 688 s.

As, N., Koç, H., Doğu, D., Atik, C., Aksu, B., Erdinler, S. (2001). Türkiye'de Yetişen Endüstriyel Öneme Sahip Ağaçların Anatomik, Fiziksel, Mekanik ve Kimyasal Özellikleri, Seri B, Cilt 51, Sayı 1.

Aslanoğlu Evyapan, G., Tokol, A. S. (2000). Peyzaj Tasarımı Ders Notları, Orta Doğu Teknik Üniversitesi, Ankara

Aytuğ, B., Görcelioğlu, E. (1987). Gordiyon Kral Mezarında Ağaç Malzeme ve Mobilya Buluntuları, ìstanbul Üniversitesi Orman Fakültesi Dergisi, Seri A, Cilt 37 Sayı 1.

Başal M, Memlük Y., Yılmaz O., Kurum, E. (1997). Peyzaj Konstrüksiyonu, Ankara Üniversitesi Ziraat Fakültesi Yayınları: 1484, Ders Kitabı:445, Ankara, 188s.

Beceren Öztürk, R. (2005). Türkiye'de Yetişen Sarıçamdan Üretilen Lamine Ahşap Kirişlerin Mekanik Özelliklerinin Araştırılması, İstanbul Üniversitesi, Fen Bilimleri Enstitüsü, Doktora Tezi.

Bozkurt, A.Y. (1986). Ağaç Teknolojisi, İstanbul Üniversitesi, Orman Fakültesi Yayınları, İstanbul, Yayın No: $3403 / 380$.

Bozkurt, Y., Göker, Y., Erdin, N. (1993). Emprenye Tekniği, İstanbul Üniversitesi Orman Fakültesi, i. Ü. Yayın No:3779, O. F. Yayın No: 425, ISBN 975-404-327-2, istanbul, 429 s.

Canbakal Ataoğlu, N. (2016). Bir Tasarım Modası Olarak Ham Ahşap Ve Paletler, Selçuk üniversitesi, Selçuk Teknik Dergisi. Özel Sayı 2: 1088-1099.

De Cristoforo, R. J. (1976). Wood Projects for the Garden, Ortho Books, Chevron Chemical Company, Sanfrancisco, CA, USA. pp.96.

Doğu, D., Koç, H. K., As, N., Atik, C., Aksu, B., Erdinler, S. (2001). Türkiye'de Yetişen Endüstriyel Öneme Sahip Ağaçların Temel Kimlik Bilgileri ve Kullanıma Yönelik Genel Değerlendirme, İstanbul Üniversitesi Orman Fakültesi Dergisi, Seri B 51(2): 69-84.

Frühwald, A., Pohlmann, C. (2002). 'Nachhaltiges Bauen mit Holz, Informationsdienst Holz, Deutsche Gesellschaft für Holzforschung, München.

Gezer, H. (2012). Mekânı Kavrama Sürecinde Algılama Bileşenleri, İstanbul Ticaret Üniversitesi Sosyal Bilimler Dergisi. 21(1):1-10.

Göker, Y., Kurtoğlu, A. (1987). Bazı Önemli Açık Renkli Afrika Ağaç Türleri, İstanbul Üniversitesi, Orman Fakültesi Dergisi, Seri B, Cilt 37, Sayı 1.

Gündüz, G., Yıldııım, N., Şirin, G., Onat, S. M. (2009). Ak Dut Ağacının Anatomik, Kimyasal, Fiziksel ve Mekanik Özellikleri, Düzce Üniversitesi Ormancılık Dergisi, Yayın No: 5 (1): 131-149.

Huş, S. (1958). İ̆ne Yapraklı Ağaçlardan Elde Edilen Eteri Yağlar, İstanbul Üniversitesi Orman Fakültesi Dergisi. Seri B. Cilt VIII. Sayı 1.

Kandemir, S., Bayar Muluk, N. (2016). Koku fizyolojisi ve koku testleri: derleme, Turkish Journal of Clinics and Laboratory, 7(2): 48-53. 
Karadağ, A. A., Korkut, D. S., Korkut, S., Kesim, G. A. (2009). Peyzaj Mimarlığında Ahşap Kullanımı, Bartın Orman Fakültesi Dergisi, I. Ulusal Batı Karadeniz Ormancılık Kongresi Bildiriler Kitabı, Özel Sayı, Cilt II, Sayfa: 501509.

Karadağ, A. A., Korkut, D. S., Korkut, S., Köylü. P., Akıncı Kesim, G. (2016). Türkiye'de Ahşap Donatı Elemanı Üretiminin Değerlendirilmesi, Düzce Üniversitesi Orman Fakültesi, Ormancılık Dergisi 12(2): 241-257.

Sivrikaya, H. (2008). Odunda Doğal Dayanımı Etkileyen Faktörler, Bartın Orman Fakültesi Dergisi 10 (13): 66-70.

Süel Yazıcı, A. B. (2007). Bir Sosyal Çevre Olarak Yerleşke Kimliği Oluşmasında Donatı Elemanlarının Önemi: Başkent Üniversitesi Bağııca Yerleşkesi Üzerine Alan Çalışması, Doktora Tezi, Ankara Üniversitesi Sosyal Bilimler Enstitüsü, Ankara, 225s.

Şirin, G., Aydemir, D. (2016). Sonlu Elemanlar Metodunun Ahşap Malzemelerde Kullanımına ilişkin Bir Araştırma, Bartın Orman Fakültesi Dergisi 18 (2): 205-212.

Topay, M., Kuş Şahin, C. (2016). Dış Mekânın Etkin Kullanımında Ahşap Malzeme Seçimi, Plant Peyzaj ve Süs Bitkiciliği Dergisi, Sayı 18: 154-158.

Winterbottom, D. M. (2000). Wood in the Landscape, A practical guide to specification and design, John \& Wiley Sons, NY. 